\title{
ARMOR PROTECTION FOR HEAVY GUNS IN BATTLESHIPS.*
}

BY WM. C. FOLEY.

In a modern battleship, where a high rate of speed is required, one of the chief aims of the designer, in the disposition of the main armament, is to ensure it a maximum protection with a minimum of weight; consequently, wherever weight can be saved without detracting from the offensive and defensive power, or seaworthiness of the vessel, it is of great importance.

The system of mounting the heavy guns singly in several armored stations at a considerable distance apart, interferes with the efficiency of a good auxiliary armament; it increases and complicates the amount of gear necessary for training the guns, and for hoisting the ammunition to the guns; it also increases the weight of armor necessary for protection, as compared with the system of mounting the heavy guns in pairs in a less number of protected stations.

The design that combines great offensive power with a minimum weight of armor, and at the same time has the guns well protected, is the system of mounting the heavy guns in pairs in two armored stations placed at each end of the vessel, and working independently of each other, so that there is no fear of simultaneous disablement from an enemy's gun fire, as in this arrangement all the heavy guns can be utilized with the auxiliary armament for a broadside discharge. 'To carry guns of the largest calibre now made, ships must necessarily be of large dimensions and heavy displacement, and I think that the very heavy battleships that have been constructed, and are still being built, in foreign navies, are no doubt very good as gun platforms, but they have the drawback of not being such good sea vessels, and the point of seaworthiness has been partly lost sight of in

* Read at the Stated Meeting of the Section of Engineers and Naval Architects, April 24, I894. 
the attempt to form huge floating batteries. These large vessels roll very heavily in a seaway, and the weights being local, so to speak, the strains that are brought to bear on a vessel in such a condition are enormous, to withstand which she must be strengthened in such a manner that the weight of the hull is increased considerably at the cost of the armor protection. The writer believes that in the future, when we have gained more practical knowledge of the working of vessels of this class at sea, the limit of size for a battleship will not exceed i 2,000 tons displacement. 'Thus in reducing the size of our battleships we can increase their number for the same amount of money expended.

As the gurs of large calibre that have been tried in different navies have not been altogether successful for various

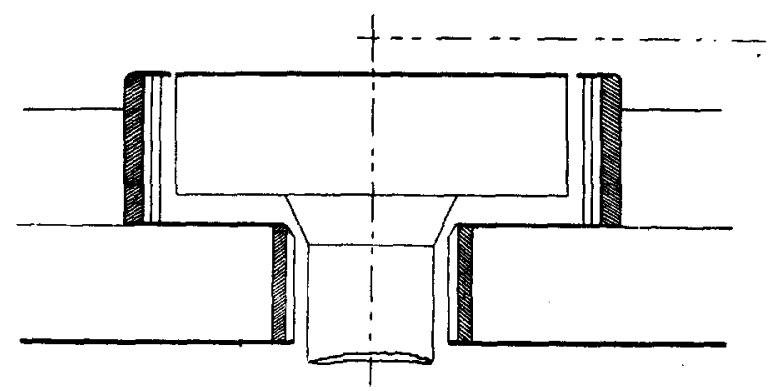

Fig. I

reasons, guns of a smaller calibre are now being adopted; in the British Navy, the 13.5-inch, sixty-seven ton gun being used, but the most recent ships will have I2-inch guns. In the Italian Navy they use a gun of sixty-eight tons; and a forty-five ton gun is langely used in the French Navy; and it is probable that the future guns for ships will decrease rather than increase in size, so that for illustration I have chosen a mounting suitable for I 2-inch guns.

There are two systems of mountings for heavy guns, both of which are in common use; namely, "barbette mounting" and "turret mounting ;" and we will now briefly review the advantages and disadvantages of each.

Barbette Mounting.-In the earlier ships built on the barbette system, the redoubt armor was only carried down 
sufficiently to protect the turntable, having a thick plated bottom, the weight of which was transmitted to the hull by a circular support and by the bulkheads below. The ammunition for the guns was either hoisted up direct into the turntable, as in Fig. $I$, in which case an armored cylinder was carried from the protective deck to the barbette floor, for protection of same; or it was hoisted up at the rear end and outside of the turntable, as in Fig. 2.

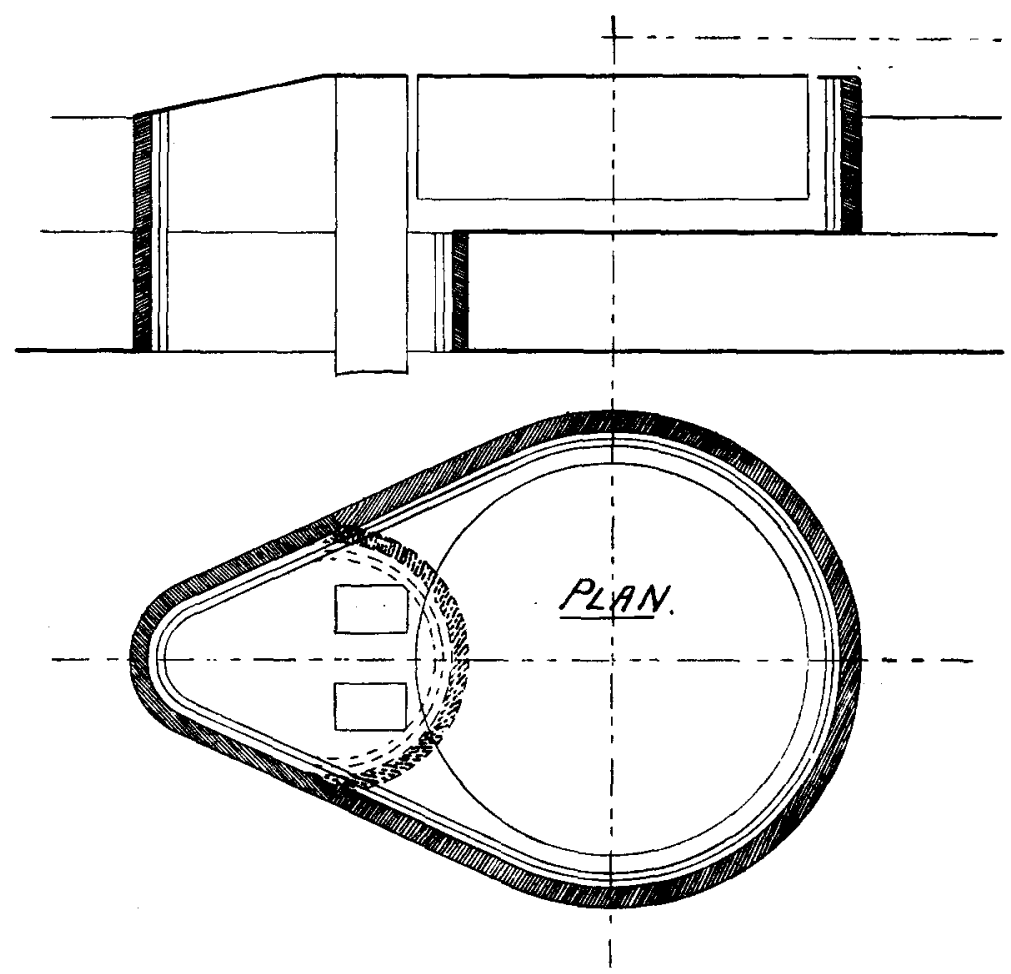

FIG. 2.

In this case the rear plates of the redoubt armor were carried down to the protective deck and an arc of armor worked round the hoists below the barbette floor. The total weight of armor, including a three-inch floor plate, was only 340 tons in Fig. $I$; and in Fig. 2, which is a totally different arrangement, 430 tons. But with the development of quickfiring guns, throwing shells of high explosive power, this 
system of armoring barbettes did not afford sufficient protection, as a shell bursting between decks underneath the barbette floor, would throw the turntable out of gear and thus cause the disablement of the guns; therefore, in barbettes, the armor had to be increased in depth, as shown in Figs. 3 and 4 , an arrangement which completely protects the gun mountings. With this arrangement of armor, a shell bursting inside the ship would have to pierce the redoubt armor before any damage to the gun mounting could be sustained.

Fig. 3 represents an armored barbette, with the armor carried down to the protective deck, which, in conjunction with the side armor of the ship, completely protects the turntable and all gear. The weight of armor in this arrangement is 450 tons, or IIo tons more than in Fig. I.

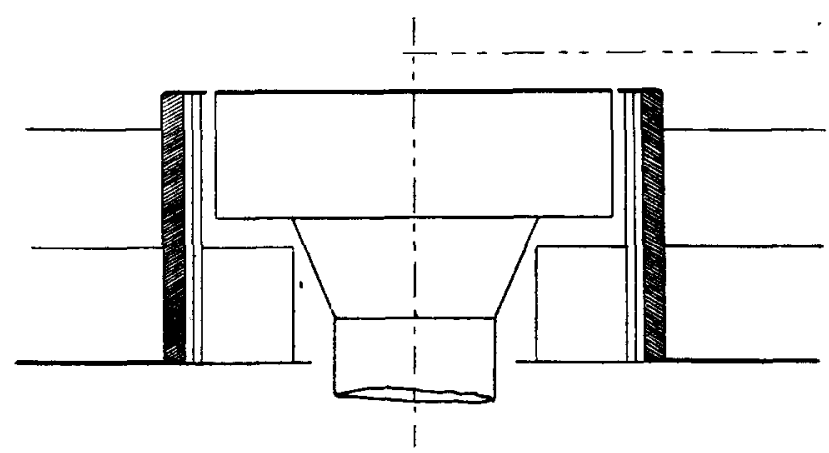

FIG. 3 .

In this type of barbette, the ammunition is carried from the ammunition-passing room up through a center cylindrical tube directly to the guns. This arrangement of barbette appears to combine the highest economy in weight of armor with the maximum protection; but its disadvantages are that the carrying of the ammunition directly up into the turntable necessitates the crowding of a good deal of gear into a small space. The rammers also are placed in the turntable, being of the telescopic type; and the turning engine must be situated below the protective deck and geared up to the turning rack. In some designs a hydraulic turning engine is fitted in the turntable, and works with a short 
shaft and pinion on to a rack underneath the turntable, but this adds still further to the crowding of gear in the turntable, which is not to be commended.

Fig. 4 represents a barbette with the armor carried down to the protective deck. The armor at the rear end can be decreased in thickness, as in conjunction with any diagonal

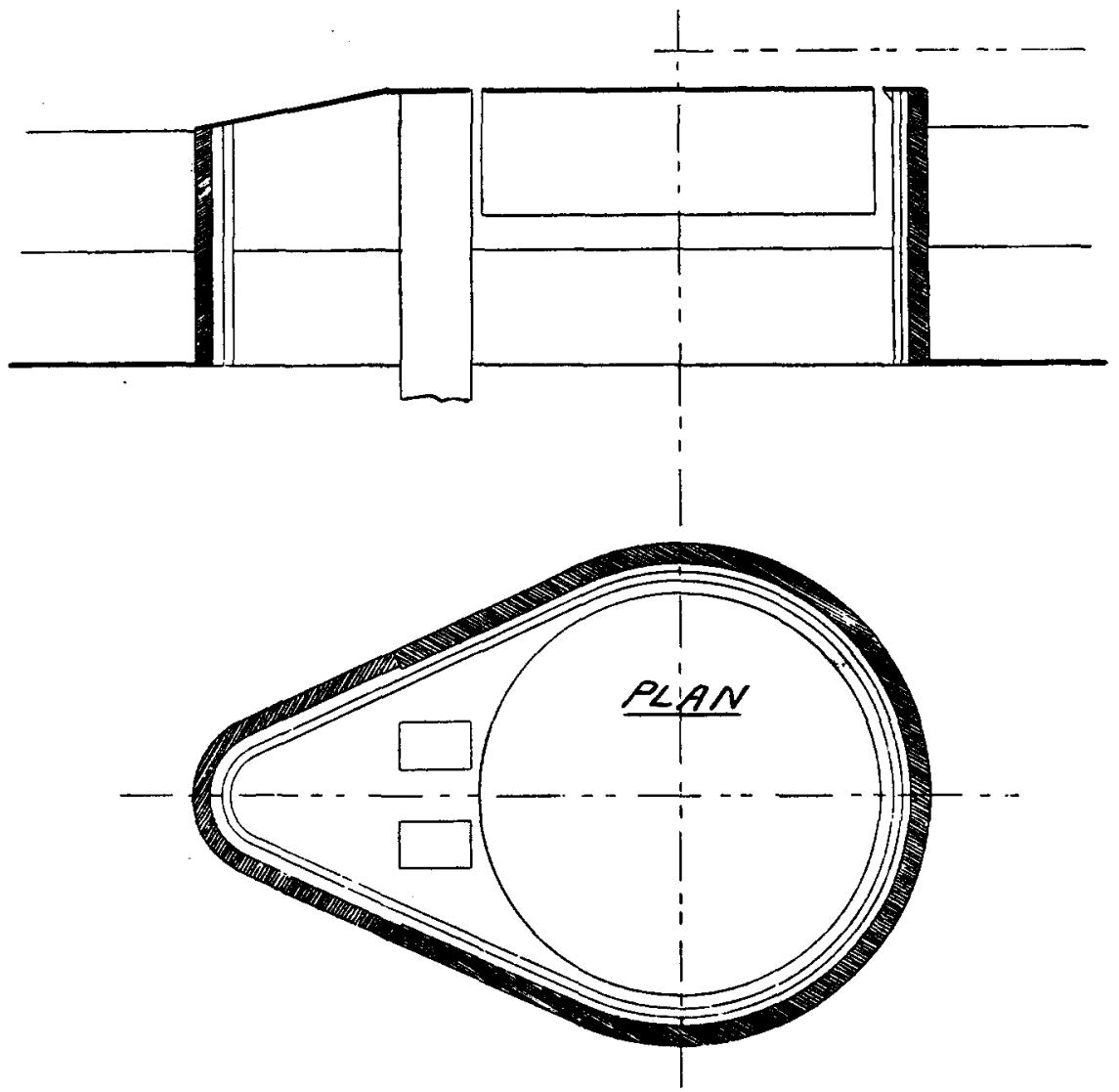

FIG. 4.

armor that may be fitted there is less likelihood of a shot striking here. The armor is shaped as shown in the plan view, Fig. 4. The ammunition comes up the hoists at the rear or narrow end, where the rammers are situated, and loads from the cage in the hoists into the guns. In this arrangement the guns have to be trained into the fore and 
aft direction, after each discharge, to reload. This is a disadvantage, as compared with the plan shown in Fig. 3, in which loading can be done in any position; but a rate of discharge of one round in less than two minutes can be maintained, which is very little below that of Fig. 3. The turning engine, which may be either steam, hydraulic or electric, can be placed below the barbette floor, and with a short shaft and pinion wheel work on to a rack, which is placed at the extreme diameter of the turntable; this ensures smoother working and less strain on the engine.

Electric hoisting and turning engines have been fitted in some cruisers of the French Navy, and in a battleship for the Chilian Navy, and, I believe, have worked well.

The weight of armor in this barbette (Fig. 4), is about

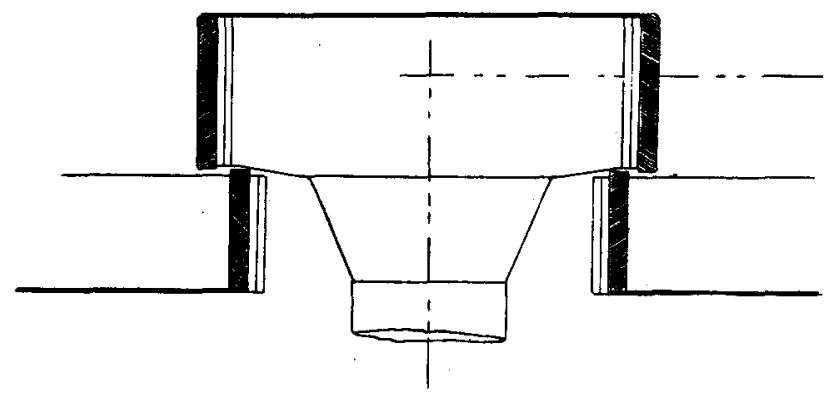

FIG. 5.

sixty-five tons more than that of Fig. 3, but the turntable itself is much lighter, owing to the absence of the center ammunition cylinder and gear attached to same.

Having now given a rough idea of the arrangement and working of two different types of barbettes, we will now proceed to contrast them with turret mountings.

Turret Mounting.-In the turret mounting, the protection of the heavy guns consists of fifteen-inch armor on the turret, redoubt armor also being fitted for protection of turret base and ammunition apparatus.

Fig. 5 represents a turret arrangement, the axis of the guns being seventeen feet above L.W.L., the vessel having a freeboard of eleven feet forward; weight of turret and redoubt armor being 406 tons. 
Now, for sea-going battleships, a high freeboard forward is advisable, as it is possible to maintain, with such ships, a high rate of speed, and fight the guns in a seaway. In obtaining the freeboard, however, we must keep our weight as low as possible so as to have a stable ship and steady gun platform. At the same time we must not minimize our protection. Although eleven feet is enough freeboard for a coast defense vessel, or for the after end of a sea-going vessel, it is not sufficient for the forward end. A reference to the following table will show that by adopting the barbette arrangement (Fig. 3) instead of the turret, we get a deck more forward, giving us a freeboard of eighteen feet with

TABLe.

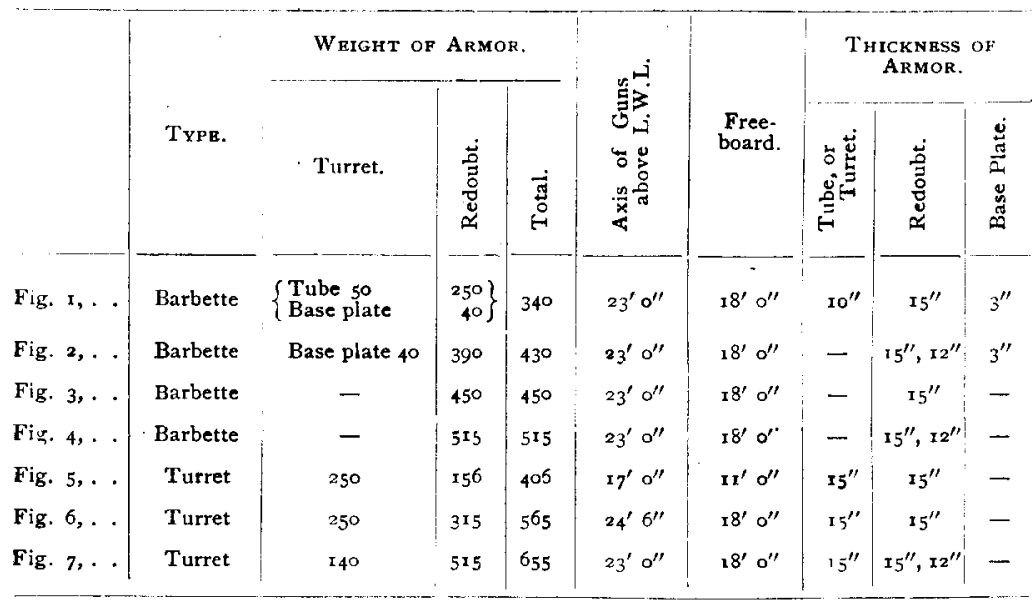

an increase of only fifty tons of armor, the center of gravity of said weight being almost the same in each case.

Fig. 6 represents a turret, the arrangement and working of which are the same as for the barbette, Fig. 3. The axis of the guns above L.W.L. is twenty-four feet six inches, but the weight of armor necessary for protection is considerable, namely 565 tons.

But in the turret arrangement the total weight of the turntable exceeds that of the turntable in the barbette arrangement by 300 tons, and this weight it must be remembered is very high up, which is a considerable factor when 
the stability is concerned. Then again the power of the turning engines must be increased to turn this extra weight.

Fig. 7 represents a turret mounting, the arrangement and working of which are the same as in the barbette, Fig. 4. The total weight of armor, in Fig. 7 , is ninety tons in excess of that of Fig. 6, this increase being in the redoubt armor; but owing to the turntable being lower (thus reducing the depth of the turret armor), the turret armor is I Io tons less in weight than that of Fig 6 , thus reducing the total weight of the turntable.

Other methods of working turret armor have been tried, such as having the armor on the turrets sloping. This reduces the weight of armor, but it curtails the room inside the turntable; and the armor is also difficult to roll and

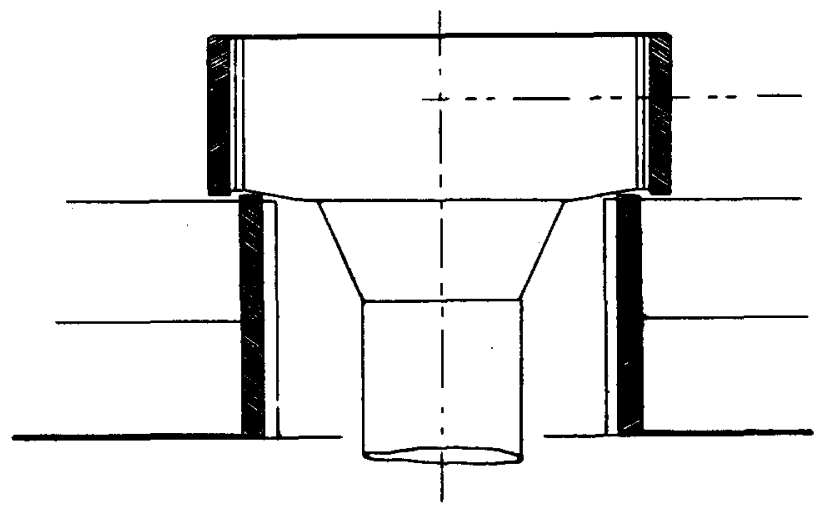

FIG. 6.

machine to the proper bevel at top and bottom. But this can be partly overcome by working the armor plates flat. thus forming a polygon in plan view. This method is adopted in the barbettes in the Italian Navy.

Backing for Armor.-The structure for holding the redoubt armor plates in position is generally formed as follows: Two thicknesses of steel plates are worked for the depth and extent of the armor, stiffened by vertical and horizontal bracket plates and angles, connected firmly to the ship's hull, and the stiffening spaced so as to allow a good disposition of armor bolts. Wood backing is then connected to the outside surface of this structure by means 
of galvanized iron or steel bolts; the heads of which are sunk beneath the finished surface of the backing and covered with wooden dowels. Hempen grummets covered with red lead are placed underneath the washer of the nuts on the inside of the two steel plates, to ensure watertightness. The wood backing must be caulked and the seams payed with a waterproof composition; and before fitting the armor plates, a thick layer of red lead, or approved composition, should be applied on the outer surface. The wood backing is trimmed down from a template taken from the armor plate itself, so as to ensure an exact fit. The practice of fitting redoubt armor without wood backing is not to be commended, as there is always a certain amount of working

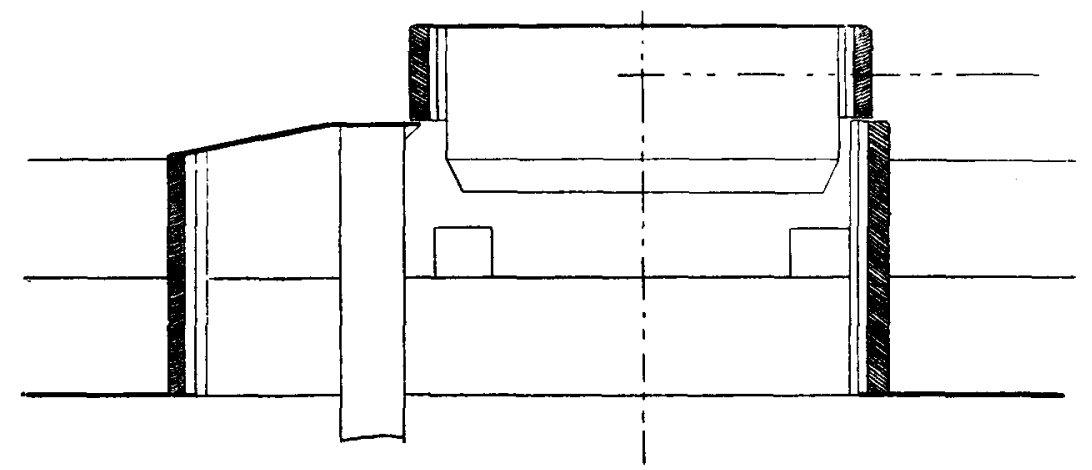

FIG. 7 .

in a seaway or from the blast of the guns; and it is easier to heave up the armor bolts and maintain the watertightness of the work when wood backing is fitted. The extra weight due to fitting backing and the slightly increased diameter of armor to fit same, is more than compensated for by the efficiency of the work done.

Armor Plates.-Great care must be exercised in the fitting of the armor plates. They should be made to fit as nearly as possible metal to metal at the butts, and caulked whereever they are so fitted. Where they do not fit accurately, small pieces of metal will be driven into the spaces and then caulked flush with the face of the plate. The plates are held in place by means of bolts, standard sizes being used 
for certain thicknesses of armor, the number being proportional to the outer surface of the plate. For fifteen inch armor one bolt is allowed for every four and one-half square feet of surface. Wherever the projection inward from the two thicknesses of plates must be reduced to a minimum, distance sleeves are not fitted, the bolt-head being heaved up against an india-rubber washer in a steel hexagonal cup, thus making the passage of the bolt through the plating watertight. When no distance sleeve is fitted the weight of the armor is taken on the thread in the plate itself, and not on the thread on the inner end of the bolt, as is usual where space will allow. The threads of armor bolts are similar to the thread of the breech plug of the modern gun, that is, each side of the thread has a different angle, the strain being on the steep side when the bolt is in tension, thus making it able to bear a greater strain than a thread of the ordinary screw type.

In comparing the barbette and turret arrangements we will take Figs. 3 and 6 , as both have the same freeboard, but the axis of guns above L.W.L. is slightly less in barbette mounting. The diameter of the armor for barbette is greater, so as to admit of a turntable of suitable size for the guns, consequently there is a slight increase in the comparison of the weights of redoubt armor; but when the weight of the turret armor is taken into account, there is a saving in the total weight in the barbette arrangement of over 100 tons, which weight is at a considerable height above L.W.L. Therefore, it may be taken that in the matter of weight and horse-power of turning engine, the barbette has the advantage. It may be said that in the barbette arrangement the guns are more exposed to damage. This is quite true, but it must be remembered that the range of these guns is over ten miles, and that probably in an engagement the firing will commence at a long range, and a gun at this distance is a small object to hit. It is probable, also, that the enemy will aim at the center or highest part of the ship, and if the guns are mounted in pairs at the ends of the vessel the chance of hitting the guns is not much greater than if mounted in a turret. 
In the turret arrangement the muzzle of the gun is exposed, and, if hit, is disabled, so that the protection to the guns is not much greater with a turret than with a barbette mounting. Then again, the men are as much protected in the barbette mounting as in the turret mounting, as the top of the turntable or turret is the same in each case, being protected by means of a thick nickel-steel plate, one or two thicknesses of thin plating being worked beneath the thick plate to which it is connected, by means of rivets countersunk top and bottom, to do away with rivet-heads inside the turntable, as a shot striking the thick plate would cause the rivet-heads to fly off, and be a source of danger to those working the guns. Thick steel hoods are placed on top to afford protection for sighting purposes. Another point worth noticing in the turret arrangement is this, that if the turret is struck by a heavy projectile of high velocity there is a chance of throwing the turntable out of gear. This is also a reason for keeping the roller path at the greatest diameter of turntable, as it adds to smoothness of working, and does not bring so much strain on the holding down clips.

Reference to the table shows that the comparison of barbette and turret mountings certainly favors the barbette arrangement, as far as weight is concerned, and as the turntable bases, turning gear, etc. (which after all is the most vital part of the mountings), are equally protected in both cases, the extra weight involved in protecting a small portion of the guns by means of a turret seems to be misplaced, as such extra weight might be employed in increasing the thickness of the redoubt or side armor.

The marked improvements in the manufacture of armor has been the means of a great saving in the weight of armor for a certain amount of protection. The race for supremacy between armor and guns has been carried on incessantly, and as the destructive power and penetrating energy of the projectile has increased, so also the defensive power of the armor has been increased.

From the old armor plate which we can all remember, to the compound armor plate with a hardened steel face, was a 
step in the right direction, and further improvements have furnished nickel-steel and Harveyized armor plates, both of which have given good results, so that now we can use armor of half the thickness and weight formerly used and still have as great protection, and as long as we can use armor around our gun stations to resist penetration, it gives us the advantage of having ourguns protected and of being able to strike a blow at any enemy.

In conclusion, the writer hopes he has placed some points before you worthy of discussion.

\section{Franklin Institute.}

\section{[Proceedings of the stated meeting, held Wednesday, May I6, 1894.]}

HaLl of the FrankLin Institute, Philadelphia, May 16, 1894

Mr. JoSEPH M. WiLson, President, in the chair.

Present, forty-six members and six visitors.

Additions to membership reported since last meeting, nine.

The Secretary read a letter from $\mathrm{Mr}$. Thomas $\mathrm{P}$. Conard, conveying his acceptance of election to the Board of Managers.

Mr. E. P. Reichhelm, of New York, read a paper describing the system and apparatus of the American Gas Furnace Company.

Mr. Louis Krumbhaar gave a description of a new apparatus designed for manifolding or producing a large number of printed copies of a document from a stenciled original made on the typewriting machine. The invention consists of an improved printing apparatus, called the "diagraph," which was exhibited and shown in practical operation by the inventor, Mr. Thomas H. Stackhouse.

Mr. Constant de Redon, of New York, exhibited a large number of specimens of aluminum soldered joints, made by the process and material used for the purpose by the Alsite Aluminum Company, of that city. He gave a practical illustration of the method of using the solder, by making a number of joints. Among the numerous exhibits presented by the company were specimens of articles of aluminum handsomely electroplated with gold and silver.

The subjects presented by Mr. Krumbhaar and Mr. de Redon were referred to the Committee on Science and the Arts for investigation.

Mr. Edward Brown described and showed the practical application of a new form of pyrometer devised by him for service in indicating temperatures up to about $2,000^{\circ}$.

The Secretary's report embraced an account of the salient features of the Manchester Ship Canal, which was illustrated with lantern views.

Adjourned.

WM. H. WAHL, Secretary. 